We found that low socioeconomic status in adulthood was related to adverse changes in control beliefs during the six year follow up (results not shown), suggesting that adult socioeconomic conditions further contribute to beliefs of low control. More information is needed on the specific socioeconomic correlates that induce beliefs of low control as these may be easier to modify than the beliefs themselves. Low job control may be one of these conditions. ${ }^{5}$ Other studies with larger numbers are needed to examine the behavioural or psychophysiological pathways through which perceived control affects mortality. Our findings emphasise that only by examining psychological mechanisms more thoroughly can we determine the complex pathways through which social structure affects individual disease and mortality.

The study was conducted in close collaboration with the Public Health Services of the Dutch city of Eindhoven and the region of South-East Brabant. We thank Michel Provoost and Ilse Oonk for carefully constructing the database and Mariel Droomers for providing comments on previous drafts of the paper.
Contributors: $\mathrm{HB}$ was the main author, formulated the hypothesis, carried out the analyses, interpreted data, and was partly responsible for data collection. CS helped with writing and interpreting data and was partly responsible for data collection. JPM was principal investigator, helped with writing and interpreting data, was responsible for data collection, and is guarantor for the study.

Funding: Dutch Ministry of Public Health, Welfare, and Sports and the Dutch Prevention Fund.

Competing interests: None declared.

1 Syme SL. Control and health: a personal perspective. In: Steptoe A, Appels A, eds. Stress, personal control and health. London: Wiley, 1989:3-18.

2 Bosma $\mathrm{H}$, Mheen $\mathrm{HD}$ van de, Mackenbach JP. Social class in childhood and general adult health in adulthood: a questionnaire study of contribution of psychological attributes. BMJ 1999;318:18-22

3 Mackenbach JP, Mheen HD van de, Stronks K. A prospective cohort study investigating the explanation of socio-economic inequalities in health in the Netherlands. Soc Sci Med 1994;38:299-308.

4 Rotter J. Generalized expectancies for internal versus external control of reinforcement. Psychol Monogr 1966;80:1-28.

5 Marmot MG, Bosma H, Hemingway H, Brunner E, Stansfeld S. Contribution of job control and other risk factors to social variations in coronary heart disease incidence. Lancet 1997:349:235-9.

(Accepted 7 September 1999)
Health Care

Evaluation Unit,

Department of

Public Health

Sciences,

St George's

Hospital Medical

School, London

SW17 0RE

Joanne Lord

lecturer in health

economics

Peter Littlejohns professor

Rachel Churchill

senior research fellow

continued over

BMJ 1999;319:1470-1

website

extra

A table with

baseline data is on

the BMJ's website

www.bmj.com

\title{
Cost effectiveness analysis of inhaled anticholinergics for acute childhood and adolescent asthma
}

\author{
Joanne Lord, Francine M Ducharme, Ronald J Stamp, Peter Littlejohns, Rachel Churchill
}

A recent systematic review by the Cochrane Airways Group showed that adding multiple doses of anticholinergics to $\beta_{2}$ agonists is safe and effective in improving lung function and avoiding hospital admission for school aged children and adolescents attending casualty departments with severe acute asthma. $^{1}$ The estimated reduction in the risk of admission was $9.4 \%$ ( $0.4 \%$ to $18.4 \%)$. This intervention presumably improves bronchodilatation until systemic corticosteroids take effect. Evidence of cost effectiveness, however, is lacking. To clarify whether scarce health resources should be spent on this intervention we conducted an economic evaluation.

\section{Methods and results}

We used various assumptions to estimate the financial implications of treatment (see table on the BMJ's

Results of baseline analysis, with uncertainty ranges estimated by probabilistic sensitivity analysis

\begin{tabular}{lcc} 
& \multicolumn{2}{c}{ Per severe case treated } \\
\cline { 2 - 3 } & Best estimate & Uncertainty range \\
\hline Admissions avoided $\dagger$ & 0.09 & $0-0.18$ \\
\hline Cost of treatment $\ddagger$ & $£ 0.75$ & $£ 0.28-£ 1.40$ \\
\hline Savings due to avoided admissions§ & $£ 81$ & $£ 0-£ 158$ \\
\hline Cost of treatment per admission avoided & $£ 8$ & $£ 1-£ 47$ \\
\hline Net monetary saving to the health service & $£ 80$ & $£ 0-£ 157$ \\
\hline
\end{tabular}

*Interval containing $95 \%$ of 5000 simulation replications. †Risk difference estimated by meta-analysis. ${ }^{1}$ ¥Cost of ipratropium bromide 25p per $0.25 \mathrm{mg}$ (from British National Formulary March 1999), and total dose per patient $0.625 \mathrm{mg}$ (median for multiple dose protocols included in the meta-analysis ${ }^{1}$ ). Authors assumed that one mild to moderate case is treated for every five severe cases treated.

$\S$ Mean cost of non-elective inpatient admissions £860 (NHS Executive's reference costs 1998 (HRG D21 and D22)). ๆCost of treatment divided by the number of admissions avoided.

${ }^{* *}$ Savings due to avoided admissions minus the cost of treatment. website). The costs of drug administration were not included, as anticholinergics are always given with $\beta_{2}$ agonists and involve little additional manipulation. The cost of nebulisers, other drugs, and the casualty attendance were also excluded. No consideration was given to possible changes in length of stay in casualty. The effect of changing the various assumptions was tested by simple, one way, sensitivity analysis, and by multivariate probabilistic sensitivity analysis. ${ }^{2}$ The latter is a simulation approach that enables estimation of uncertainty ranges containing $95 \%$ of replicated results. ${ }^{3}$

We estimated that treatment would cost about $£ 8$ (uncertainty range $£ 1$ to $£ 47$ ) per admission avoided (table). This implies a net saving of $£ 80$ ( $£ 0$ to $£ 157$ ) per severe case treated. Varying the risk reduction within $95 \%$ confidence limits varied the mean net saving from $£ 3$ to $£ 157$ per severe case treated. More precision is expected when the Cochrane review is updated. Varying the cost of hospital admissions within the interquartile range for English providers (£620 to $£ 907$ ) varied the mean savings from $£ 58$ to $£ 85$ per severe case treated. Changes to the dose and unit cost of ipratropium had very little effect on the results.

Further assumptions were used to extrapolate the findings to a national level. About 7200 children aged 5-15 years are admitted from casualty with a diagnosis of asthma each year (hospital episode statistics 1988 to 1996). About $40 \%$ of children in this age group attending casualty with asthma are admitted. ${ }^{4}$ We assumed that $50 \%$ of people with asthma attending casualty have severe asthma. The rate of uptake of the review recommendations was assumed to be $5 \%$ a 
year; therefore an additional $5 \%$ of eligible patients would be treated in the first year, $10 \%$ in the second year, and so on. If doctors treated patients with mild or moderate asthma, this would add to treatment costs with no evidence of clinical benefit. We assumed that for every five patients with severe asthma who were treated, one patient with mild or moderate asthma would be treated. Costs were discounted at an annual rate of $6 \%$.

Net savings were estimated to be $£ 437800$ ( $£ 3700$ to $£ 1078100$ ) over five years in England. An increase in the number of patients for whom treatment is indicated, or in the proportion of eligible patients who are treated, leads to a proportionate increase in savings. For example, if all eligible patients were to be treated, after five years the estimated savings would be quadrupled. A reduction in the annual discount rate from $6 \%$ to $3 \%$ leads to an increase of $£ 47600$ in expected savings. Increasing the ratio of inappropriate to appropriate treatment from $20 \%$ to $100 \%$ leads to a small decrease (£2800) in expected savings.

\section{Comment}

The addition of multiple dose anticholinergics to inhaled $\beta_{2}$ agonists for children and adolescents attending casualty with severe acute asthma would result in savings in health service resources. This finding is robust to changes in modelling assumptions, although some uncertainties remain. The personal value of the health effects and avoided hospital admissions provide additional benefits that have not been quantified in this analysis.

We thank Paul Jones and Steve Milan of the Cochrane Airways Group; Janine Bestall for her help in literature searching; Richard Atkinson for providing data on hospital episode statistics; and Debbie Latouche and Martyn Partridge for providing data from the UK National Asthma Task Force audit. A referee gave very helpful comments on an earlier draft of the report

Contributors: RJS had the original idea for the project. JL conducted the computer modelling and drafted the report FMD gave specific advice on the systematic review and the modelling assumptions. All contributors participated in the design of the project and commented on drafts of the report.JL will act as guarantor.

Funding: The health care evaluation unit is supported by the research and development offices of the South East and London regional offices of the NHS Executive.

Competing interests: None declared.

1 Plotnick LH, Ducharme FM. Should inhaled anticholinergics be added to $\beta_{2}$ agonists for treating acute childhood and adolescent asthma? A systematic review. BMJ 1998;317:971-7.

2 Briggs A, Sculpher MJ, Buxton MJ. Uncertainty in the economic evaluation of health care technologies: the role of sensitivity analysis. Health Economics 1994;3:95-104.

3 Lord J, Asante MA. Estimating uncertainty ranges for costs by the bootstrap procedure combined with probabilistic sensitivity analysis. Health Economics 1999;8:323-33.

4 Partridge MR, Latouche D, Trako E, Thurston JGB. A national census of those attending UK accident and emergency departments with asthma. $J$ Accident Emerg Med 1997; 14:16-20.

5 Stell IM. Asthma management in accident and emergency and the BTS guidelines-a study of the impact of clinical audit. J Accident Emerg Med 1996;13:392-4

(Accepted 24 August 1999)
Departments of Pediatrics and of Epidemiology and Biostatistics,

Montreal Children's Hospital, McGill University, 2300 Tupper Street,

Montreal, Quebec,

Canada H3H 1P3

Francine M

Ducharme associate professor

Wessex Institute for Health Research and Development, Biomedical Services Building (mailpoint 727), University of

Southampton, Southampton SO16 7PX

Ronald J Stamp honorary senior research fellow

Correspondence to: J Lord

j.lord@sghms.ac.uk

\section{A memorable patient Unforeseen consequences}

It was not long after I had arrived to take over a singlehanded practice in a rural part of Ireland that I first met Jean. I was struck by her big hands, jutting chin, and rather waxy facial features. The fact that she had hypertension and diabetes lent support to my clinical impression of acromegaly and that this had gone unnoticed in over three years of attendance at the hospital medical outpatient department added to the glow of satisfaction when the diagnosis was confirmed by an endocrinologist.

Jean was glad to have a diagnosis but was nervous of the prospect of surgery when a computed tomogram showed the pituitary tumour responsible. Her daughter had died some years earlier of a brain tumour and neurosurgery was linked in her mind with this. Thanks to a skilled neurosurgeon (the same man who had operated on her daughter) everything went well and Jean had her tumour resected.

Six months later at routine follow up, a scan raised the possibility of a middle cerebral artery aneurysm, an unrelated condition which might never have been diagnosed normally. An angiograph confirmed bilateral middle cerebral artery aneurysms and Jean was admitted to have them clipped. The right artery was clipped but she developed a hemiparesis which resolved fairly quickly. It was decided to readmit her at a later date to clip the left side.

The experience frightened Jean and she was dubious about further surgery. I spoke with the neurosurgeon who said that about one patient in 20 would develop spasm following surgery and this could give a stroke-like effect. However, he thought that the risk of surgery was less than the risk of an untreated aneurysm. Jean made a pilgrimage to Lourdes.

Two months later Jean decided to go ahead with the operation. Postoperative recovery was slow and unfortunately she developed another hemiparesis dysphasia and became completely dependent on nursing staff.

Now three yeas on, Jean is in a nursing home. Her hemiparesis has resolved considerably, but she is unable to speak and seems to have a global dysphasia. Her husband, Michael, attends me regularly. He lives alone about 15 miles from the nursing home and visits Jean nearly every day. He blames no one for what has happened. He accepts that the doctors made their decisions in good faith and after careful consideration.

If I come across another patient with signs and symptoms like Jean I would undoubtedly refer that patient to an endocrinologist. However, I feel sad and humbled by Michael's loneliness and cannot help wondering whether or not Jean might still be living with him albeit unaware of her acromegaly and dilated middle cerebral arteries, were it not for the arrival of the new doctor and his clever diagnosis.

Garrett Igoe general practitioner, Virginia, County Cavan, Republic of Ireland

We welcome articles of up to 600 words on topics such as A memorable patient, A paper that changed my practice, My most unfortunate mistake, or any other piece conveying instruction, pathos, or humour. If possible the article should be supplied on a disk. Permission is needed from the patient or a relative if an identifiable patient is referred to. We also welcome contributions for "Endpieces," consisting of quotations of up to 80 words (but most are considerably shorter) from any source, ancient or modern, which have appealed to the reader. 